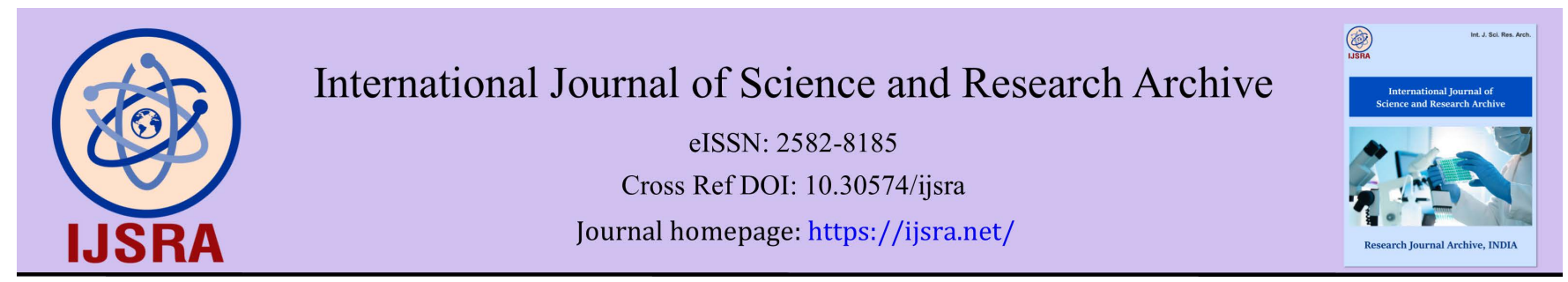

(RESEARCh ARTICLE)

\title{
Antimicrobial activity of Punica grantum leaves
}

\author{
Thammanna Gowda SS *, Parimala B Hanumesh and Manjula RV \\ Adichunchanagiri Institute for Molecular Medicine, Adichunchanagiri Institute for Medical Sciences, Adichunchanagiri \\ University, BG Nagara-571448, Karnataka, India.
}

International Journal of Science and Research Archive, 2021, 03(02), 214-217

Publication history: Received on 11 September 2021; revised on 21 October 2021; accepted on 23 October 2021

Article DOI: https://doi.org/10.30574/ijsra.2021.3.2.0162

\begin{abstract}
Natural phytochemicals isolated from medicinal plants acts as inhibitors for pathogenic microorganisms which causes contagious diseases to human beings. The present study was done to explore the antimicrobial activity of aqueous and aqueous-ethanol extract of Punica grantum leaves. The phytochemical analysis of both the extracts revealed the presence of total phenolics \& flavonoids at varied concentration. The antimicrobial activity of the extracts was carried out by disc diffusion method. Both the aqueous and aqueous-ethanol extract showed the antimicrobial activity against S. aureus, Shi. dysentriae \& Shi. flexineri. The antimicrobial activity of the Punica grantum leaves extracts could be attributed by the presence of phenolics and flavonoids.
\end{abstract}

Keywords: Punica grantum; Phenolics; pathogen; Antimicrobial.

\section{Introduction}

Microbial diseases are highly contagious and the major global threat to human life globally [1]. Varieties of antibiotics have been discovered and used to treat against the microbial diseases. During the course of treatment, microbes develop resistant against these antibiotics [2]. Many medicinal plants have been used in India \& worldwide to compensate the burden caused by synthetic antibiotic resistant pathogens. From past quarter century, a new trend has been developed in researchers to carry out research extensively on medicinal plants and were able elucidate their antioxidant, antimicrobial, anticancer, antidiabetic properties etc. Now a days, herbal products are used as dietary supplements to improve their health since they have no side effects as compared to the synthetic products. More than $80 \%$ of the world's population depends on natural herbal product for their primary health care needs [3]. The use of traditional medicine is widespread in India \& china. The antimicrobial activity of the polyphenols, tannins and flavonoids present in medicinal plants is well established $[4,5,6]$. These secondary metabolites of medicinal plants have many health benefits which would solve the problem of drug resistance.

Punica granum belongs to the Punicaceae family and is cultivated in warm climate areas of South East Asia and other parts of the world. Fruits, peels and roots of pomegranate have been used in herbal remedies in India. Pomegranate peels have been used for treating dysentery [7,8]. The seeds have been used in treating various diseases [9,10]. But the leaves of Punica granum is rarely used as a herbal medicine. The present study demonstrates the in-vitro antimicrobial activity of aqueous and aqueous ethanol extracts of Punica granum leaves.

\footnotetext{
${ }^{*}$ Corresponding author: Thammanna Gowda SS

Adichunchanagiri Institute for Molecular Medicine, Adichunchanagiri Institute for Medical Sciences, Adichunchanagiri University, BG Nagara-571448, Karnataka, India.

Copyright (C) 2021 Author(s) retain the copyright of this article. This article is published under the terms of the Creative Commons Attribution Liscense 4.0.
} 


\section{Material and methods}

\subsection{Plant materials}

Pomegranate leaves were procured from local horticulture farm, B.G. Nagar, Karnataka, India. Leaves were properly removed from twigs and washed with double distilled water to remove the dust and unwanted substances. Then, water was removed by pressing with blotting paper and used for extraction.

\subsection{Preparation of extracts}

$10 \mathrm{gm}$ of fresh leaves were crushed well with $100 \mathrm{ml}$ of $50 \%$ ethanol in water by using pestle and mortar. Mixture was filtered through whatman no. 1 followed by centrifugation (5000rpm for 10 mins at $20^{\circ} \mathrm{C}$ ) and collected the supernatant separately. Then concentrated the supernatant using vacuum evaporator (D-Lab, USA). The concentrated pomegranate leaf extract (PLE) was stored at $4^{\circ} \mathrm{C}$ for further analysis.

\subsection{Phytochemical analysis and total phenolic content}

Phytochemical analysis was done to determine the active constituents of the pomegranate extract.

\subsubsection{Total phenolics}

Total phenolics was determined according to the method of Folin Ciocalteu reaction (11) with minor modifications using gallic acid as a standard (0-100ug). Various concentrations of water and $50 \%$ ethanolic extract of pomegranate leaf extracts (ranging from $0-100 \mu \mathrm{g}$ ) were taken in series of test tubes \& the volume was made up to $500 \mu \mathrm{l}$ with distilled water. $500 \mu \mathrm{l}$ of the Folin-ciocalteu reagent was added to each tubes, the mixture was allowed to stand for 10 minutes followed by the addition of $1.0 \mathrm{ml}$ of $20 \%$ Sodium carbonate, incubated for 10 minutes at $37^{\circ} \mathrm{C}$. Absorbance was recorded at $750 \mathrm{~nm}$ and the concentration was calculated (Results shown in a table-2).

\subsubsection{Flavonoid estimation}

Total flavonoid content was quantified with minor modification (12) by using Quercetin as a standard. Various concentrations $(0-100 \mu \mathrm{g})$ of pomegranate leaf extracts were taken in test tubes. Made up the volume to $1.5 \mathrm{ml}$ with $95 \%$ ethanol, then $100 \mu \mathrm{l}$ of $10 \%$ of aluminium chloride, $100 \mu \mathrm{l}$ of $0.1 \mathrm{M}$ of potassium acetate was added to each tube. The total volume was made up to $2.8 \mathrm{ml}$ of by using distilled water. O.D was measured at $415 \mathrm{~nm}$ and the concentration was calculated accordingly (table-1).

\subsection{Antimicrobial activity}

\subsubsection{Microorganisms and growth}

The microorganisms were preserved at $5{ }^{\circ} \mathrm{C}$ in stab culture using Muller Hinton Broth (Himedia, India) with $1.5 \%$ MHA agar. Then cultures were activated in the respective broth at $30-32^{\circ} \mathrm{C}$ for $12 \mathrm{hrs}$.

\subsubsection{Antimicrobial activity of Pomegranate leaves extracts by disc diffusion method}

The agar dis-diffusion method was performed according standard method (13) to evaluate the inhibitory effect of pomegranate leaf extracts against several microbial strains as shown in Table 2 . In this procedure, agar plates are inoculated with a standardized inoculum (cultured in $1.0 \%$ peptone water containing $0.5 \%$ Nacl for $2 \mathrm{hrs}$ ) of the test microorganism. Then, filter paper discs (about $6 \mathrm{~mm}$ in diameter), containing the test compound ie pomegranate extracts at a desired concentration, are placed on the agar surface followed by standard antibiotic disc at the center. Then the petri dishes were incubated at $37^{\circ} \mathrm{C}$ for $18-20$ hours. The inhibition of the growth of the test microorganism and then the diameters of inhibition growth zones was measured (Table-2). The experiment was repeated three times.

\section{Results and discussion}

\subsection{Phytochemical analysis}

The phytochemical analysis showed that the concentration of total phenolics and flavonoids in pomegranate extracts. Aqueous extract has low concentration of flavonoids $(0.25 \mathrm{mg} / 100 \mathrm{~g})$ and high concentration of total phenolics $(4.5 \mathrm{mg} / 100 \mathrm{~g})$. Similarly, the aqueous-ethanol extract has more concentration of total phenolics $(10 \mathrm{mg} / 100 \mathrm{~g})$ than the flavonoids $(0.035 \mathrm{mg} / 100 \mathrm{~g})$. 
Table 1. Phytochemical analysis of pomegranate leaf extract

\begin{tabular}{|l|c|c|}
\hline \multicolumn{1}{|c|}{ Estimations } & Aqueous extract & Aqueous ethanol extract \\
\hline Total phenolics $(\mathrm{mg} / 100 \mathrm{~g})$ & 4.5 & 10 \\
\hline Flavonoids $(\mathrm{mg} / 100 \mathrm{~g})$ & 0.25 & 0.035 \\
\hline
\end{tabular}

\subsection{Preliminary screening of activity (Dis-diffusion method)}

The results obtained in the present studies shows that aqueous as well as aqueous - ethanol extracts of pomegranate leaves possess potential antibacterial activity against E. coli \& S. aureus bacteria (Table- 2).

Table 2 Antimicrobial activity of various extracts of pomegranates using disc diffusion method

\begin{tabular}{|l|c|c|c|c|}
\hline \multirow{3}{*}{ Microorganisms } & \multicolumn{4}{|c|}{ Inhibition Zone (mm) } \\
\cline { 2 - 5 } & \multicolumn{2}{|c|}{ Pomegranate extracts } & \multicolumn{2}{|c|}{ Reference } \\
\cline { 2 - 5 } & $\begin{array}{c}\text { Water } \\
\text { extract(100 } \mathbf{\mu g})\end{array}$ & $\begin{array}{c}\mathbf{5 0 \%} \text { ethanol } \\
\text { extract (100 } \mathbf{\mu g})\end{array}$ & $\begin{array}{c}\text { Gentamycin } \\
\mathbf{( 3 0 \mu g )}\end{array}$ & $\begin{array}{c}\text { Tetracycline } \\
\mathbf{( 3 0} \boldsymbol{\mu g})\end{array}$ \\
\hline S. aureus & 16 & 12 & 21 & -- \\
\hline Sh. Dysentriae & 15 & 13 & -- & 24 \\
\hline Sh. Flexineri & 22 & 18 & -- & 21 \\
\hline
\end{tabular}

Three micro-organisms were used to test their sensitivity to aqueous and aqueous ethanol extract of pomegranate. The disc diffusion method was used to test the antimicrobial potency. The zone of inhibition exhibited by the aqueous and aqueous ethanol is represented in Table-2. Compared to the aqueous ethanol extract, aqueous extract showed promising inhibitory activity against all the three microbial strains $-S$. aureus $(16 \mathrm{~mm} / 100 \mathrm{ug})$, Shigella dysentriae (15mm/100ug) \& Shigella flexineri $(22 \mathrm{~mm} / 100 \mathrm{ug})$. The broad activity against all the three pathogens is attributed by both phenolics and flavonoids in both aqueous extract and aqueous ethanol extract (10mg/ $100 \mathrm{~g})$. It clearly proved that flavonoids and phenolics present in the pomegranate leaf extracts are responsible for the antimicrobial activity.

\section{Conclusion}

The present study proved that the both aqueous and aqueous ethanol extract of pomegranate leaves extracts could inhibit most hazardous food poison causing microorganisms- S. aureus, Sh. dysentriae, Sh. flexineri very effectively. Their antimicrobial activity is mainly contributed by the presence of total phenolics in addition to the flavonoids. With the above conformity, the pomegranate leaves can be used as a natural source of antimicrobial agent to prevent the human pathogens which causes severe health problems.

\section{Compliance with ethical standards}

\section{Acknowledgments}

The authors gratefully acknowledge the Adichunchanagiri Institute for Molecular Medicine, Adichunchanagiri Institute of Medical Sciences, Adichunchanagiri University, BG. Nagara for the financial support.

\section{Disclosure of conflict of interest}

All authors declared no conflicts of interest.

\section{References}

[1] World Health Organization The evolving threat of antimicrobial resistance. Options for action. Geneva: WHO Library Cataloguing-in-Publication Data. 2012. 
[2] Ibrahim OM, Polk RE. Benchmarking antimicrobial drug use in hospitals. Expert Rev Anti Infect Ther. 2012; 10(4): 445-57.

[3] P Shanmugasundaram, Venkataraman S. Anti-nociceptive activity of hygrophila auriculata (schum) heine. Afr. J. Trad. CAM. 2005; 2(1): 62- 69.

[4] Ahmad I, Beg AZ. Antimicrobial and phytochemical studies on 45 Indian medicinal plants against multi-drug resistant human pathogens. Journal of Ethnopharmacology. 2001; 74: 113-133.

[5] Machado T, Pinto A, Pinto $\mathrm{M}$, et al. In vitro activity of Brazilian medicinal plants, naturally occurring naphthoquinones and their analogues, against methicillin-resistant Staphylococcus aureus. International J of Antimicrobial Agents. 2003; 21: 279-284.

[6] Naz S, Siddiqi R, Ahmad S, Rasool S, Sayeed S. Antibacterial activity directed isolation of compounds from Punica granatum. Journal of Food Sciences. 2007; 72: 341-345.

[7] Voravuthikunchai S, Sririrak T, Limsuwan S, Supawita T, Iida T, Honda T. Inhibitory effects of active compounds from Punica granatum pericarp on verocytotoxin production by enterohemorrhagic Escherichia coli 0157 : H7. Journal of Health Sciences. 2005; 51: 590-596.

[8] Reddy M, Gupta S, Jacob M, Khan S, Ferreira D. Antioxidant, antimalarial and antimicrobial activities of tanninrich fractions, ellagitannins and phenolic acids from Punica grantum L. 2007; 73(5): 461-7.

[9] Si-Yuan Pan, Gerhard Litscher, Si-Hua Gao, et al. Historical Perspective of Traditional Indigenous Medical Practices. The Current Renaissance and Conservation of Herbal Resources.Evidence-Based Complementary and Alternative Medicine. 2014; 1 - 20.

[10] Lal G, Meena SS. Medicinal and Therapeutic Potential of Seed Spices. Biomed J Sci \& Tech Res. 2018; 5(4).

[11] Kujala TS, Lopnen JM, Klika KD, Pihlaja k. Phenolics and betacyanins in red beetroot (Beta Vulgaris) root: distribution and effect of cold storage on the content of total phenolics and three individual compounds. J.Agric. Food Chem. 2000; 48: 5338-5342.

[12] Woisky R, Salatino A. Analysis of Propolis: some parameters and procedures for chemical quality control. J. Apic. Res. 1998; 37: 99-105.

[13] Clinical and Laboratory Standards Institute. Performance Standards for Antimicrobial Susceptibility Testing. 2014. 